\title{
MAGE antigens: therapeutic targets in hepatocellular carcinoma?
}

\author{
Pablo Sarobe, Esperanza Feijoó, Carlos Alfaro, Guillermo Mazzolini, Ignacio Melero* \\ Centro de Investigación Médica Mplicada (CIMA) y Clínica Universitaria de Navarra, Universidad de Navarra, Pamplona, Spain
}

See Article, pages 102-109

The challenging aim of cancer immunotherapy is to selectively target the cellular destruction mechanisms of the immune system towards malignant cells. Targeting requires the specificity conferred by protein sequences that are exclusively, or very selectively, expressed by tumor cells and that are recognized by effector killer lymphocytes. A tumor antigen can be defined as a biomolecule (most often a protein) that is selectively expressed in malignant cells, is presented through pathways of antigen presentation and is recognized by killer T-cells. According to their expression pattern, tumor antigens are divided into different groups: (a) tumor-specific antigens, expressed only in neoplastic cells and derived from altered self-proteins after gene mutations, translocations or transcription of alternative reading frames or from idiotypic proteins; (b) differentiation antigens, expressed by tumor cells and by their untransformed counterparts, although usually at lower levels; (c) viral tumor antigens, associated with infections by viruses causing cancer; and (d) cancer testis antigens, which are expressed in a wide variety of tumors and in male germ line.

An important line of research aimed at the identification of tumor antigens started several years ago with the pioneering studies of Boon and colleagues [1]. Based on an immunological/genetic approach, many of these antigens were characterized by the use of T-cells as probes for surrogate target cells into which gene libraries of tumor cDNA had been transfected. Thus, in the P815 mouse tumor model, this group characterized the P1A antigen by stimulating a tumor-specific cytotoxic T-cell (CTL) clone with target cells transfected with a cosmid library prepared with the cDNA obtained from P815 mastocytoma cells. Analysis of the cosmid sequence conferring susceptibility to CTL recognition led to the identification of the gene expressing the relevant tumor antigen [2]. Similarly, in

\footnotetext{
* Corresponding author. Address: Facultad de Medicina, Universidad de Navarra, C/Irunlarrea 1, 31008 Pamplona, Spain. Tel.: +34-948-425668; fax: +34-948-425649.

E-mail address: imelero@unav.es (I. Melero).
}

the case of human tumor antigens, the use of this genetic approach allowed the identification of the gene MAGE-1, encoding the antigen MZ2-E, and recognized by CTLs from patient MZ2 suffering from melanoma [3]. Further characterization showed that MAGE-1 belongs to a family of related genes, all located on chromosome X. Analysis of the expression of genes of the MAGE family has shown that they are expressed in a wide variety of tumors, but not in normal tissues, except for testicular germ cells and occasionally placenta [4].

In the following years, through the use of new tumorspecific CTL with different specificities and cDNA libraries derived from tumors, mainly from melanomas, a high number of tumor antigens have been identified. Some of these new tumor antigens belong to the group of cancer/testis antigens, since they show the same pattern of expression as genes from the MAGE family. They include genes of the BAGE, GAGE and PRAME families [5-7]. Besides the use of CTL as a searching tool, a new technology based on the serological identification of antigens by expression cloning has been developed. This technology, called SEREX, has allowed the identification of new antigens, many of them belonging to the cancer/testis group, such as NY-ESO-1, HOM-TES-15/SCP-1 and HOMTES-85 [8]. With the SEREX technology it is the antibodies present in the serum of cancer patients that are used as a probe to recognize proteins selectively expressed in cancer cells. An excellent correlation of antibody and T-cellrecognized antigens has been found. Therefore some of these antigens have been studied not only at the serological, but also at the T-cell level, since they induce both humoral and cellular immune responses. Among them, NY-ESO-1 is the best characterized, and CTL and helper T-cell responses against this antigen have been studied.

As mentioned earlier, genes of the MAGE family code for proteins that encompass several antigenic peptides capable of binding HLA class I or II molecules. These complexes can be recognized by $\mathrm{T}$ lymphocytes on the tumor cell surface. Since the MAGE genes encode antigens 
that are not expressed in normal tissues, they potentially represent safe targets for cancer immunotherapy. This has led to the use of these antigens as immunogens in clinical trials. Most of these early clinical trials using MAGEderived antigens have enrolled melanoma patients. Synthetic peptides encompassing CTL epitopes derived from MAGE proteins have been the immunogens preferentially used. Patients were immunized directly with the CTL epitope peptides, in order to induce anti-tumor CTL responses $[9,10]$. Due to the important role of CD4 T-cells in the induction of CTL responses [11], some immunization protocols have also included the CD4 T-cell epitopes, mainly peptides able to be presented by a wide number of HLA class II molecules [12]. In general, these immunization protocols have been able to induce CTL responses in some patients, and minor clinical effects were reported.

Preclinical experiments have demonstrated that dendritic cells (DC) are professional antigen presenting cells (APC) specialized in immune response induction $[13,14]$. In the case of tumors, it has been shown that immunization with these APC can break the tolerant status against tumor antigens. For this reason, subsequent immunization protocols using peptides from tumor antigens have administered the antigens pulsed onto DC [15-18]. In these cases, clear responses against immunizing antigens have been detected, together with some clinically relevant results that unfortunately were not curative. Similarly to the immunization of MAGE peptides in adjuvant, immunization with peptides using DC have been carried out using CTL epitopes in conjunction with T-helper epitopes, both belonging to tumor antigens [19]. Recently, a new vaccination protocol against MAGE antigens has been reported, using MAGE 3 protein instead of peptides, aimed at inducing both CTL and T-helper responses [20]. For other CTL-recognized epitopes, including some on melanoma antigens, an effort has been made to improve their immunogenicity. This is achieved by selecting mutations that are cross-reactive with the original sequence but with higher affinity for the HLA presenting molecule and/or the antigen T-cell receptor. When successful, these strategies produce peptides with clearly superior therapeutic activity in vaccination protocols [21]. In the case of MAGE antigens, there is no report of such improved peptide and the approach could potentially enhance efficacy.

As mentioned earlier, antigens of the MAGE family were characterized in melanoma, but they are also expressed in other tumors. Akin to other cancer/testis antigens, MAGE antigens are expressed in tumors such as breast carcinomas, gliomas, head and neck carcinomas, non-small cell lung tumors, colorectal carcinomas, and others. This finding has prompted some researchers to use these antigens in clinical trials against MAGE-expressing tumors different from melanoma [22]. In recent years, expression of MAGE antigens in hepatocellular carcinoma (HCC) has been studied, and several groups have reported an expression of different MAGE proteins in hepatic cancer cell lines as well as in tumor samples obtained from patients [23]. Thus, MAGE antigens have also become a new attractive target for the treatment of this kind of tumor.

Cloning and identification of MAGE antigens stemmed from the fact that some melanoma patients had an expansion of T-lymphocytes recognizing the antigenic peptides [1]. This finding is in line with a tumor-specific immune response in cancer patients, probably resulting from crosspresentation of tumor antigens by endogenous professional APC [24].

In this issue of the Journal, Zerbini et al. [25] show evidence indicating that the patients suffering from HCC have intratumoral and possibly circulating effector/memory lymphocytes with specificity for MAGE antigens. RT-PCR analysis has conclusively demonstrated that mRNA encoding MAGE-1 and MAGE-3 is a common feature in HCC. At least in their series of 20 cases, 17 expressed either MAGE1 ( $85 \%$ of cases) or MAGE-3 (45\% of cases). Those results, that were confirmed by immunohistochemistry, highlight the frequency of such antigens in HCC in agreement with a previous report [23].

Tumor lymphocyte infiltration was studied in biopsy samples of cases with clear evidence of accumulation of CD8 + T lymphocytes that importantly, were devoid of perforin, and thus ineffective at carrying out cytotoxicity, at least by means of this effector molecule. Previous studies correlated the intensity of lymphocyte infiltration with a better prognosis in some malignancies [26] and similar prospective studies should be extended to HCC.

Lymphocytes from some patients were studied with HLA tetramers. These are multimers of folded HLA class I molecules bound to antigenic peptides that can detect $\mathrm{T}$ lymphocytes expressing specific T-cell receptors. The authors selected MAGE-1 and MAGE-3 peptides that have been described to be immunogenic when presented by HLA-A1 and HLA-A2 molecules [27]. Using these HLA tetramers as a probe, they were able to detect MAGEspecific lymphocytes in two out of 10 cases studied.

Using antigen stimulation in culture with peptides and a cocktail of cytokines, they were able to obtain some expansion of MAGE-specific CD8 + T-cells in two other cases. Importantly and intriguingly, in one patient (patient 10) with high baseline levels of MAGE-1-specific lymphocytes, in vitro stimulation resulted in a drop of specific T-cells. This is reminiscent of the situation reported in melanoma patients whose lymphocytes, specific for MART-1 and tyrosinase, showed partial unresponsiveness in spite of being relatively abundant at baseline [28]. Like in the case of Zerbini et al. [25], most functional studies have been performed on single cases with unusually abundant tumor-specific lymphocytes and this makes us wonder whether we are only concentrating on exceptional cases. Indeed, as a consequence of technical limitations, Zerbini et al. studied in depth only one HCC case characterized by a dense infiltration of MAGE-specific T lymphocytes. MAGE1-specific $\mathrm{T}$ lymphocytes from that case had the surface 
phenotype of effector/memory $\mathrm{T}$ lymphocytes. Unfortunately, their specific lytic activity could not be tested directly ex vivo, but the lack of perforin expression suggests that they were ill-equipped at carrying out cytolytic functions. We cannot exclude, however, that a significant number of tumor cells are destroyed through perforin-independent mechanisms (TRAIL, FAS-L, cytokines). Upon in vitro restimulation, those lymphocytes displayed cytotoxic and IFN- $\gamma$ secretion abilities. In summary, results by Zerbini et al. are interesting but should be taken with caution because, as mentioned, most of their observations were made on a single patient with a high proportion of tumor reactive T-cells.

HCC is one of the most difficult tumors to treat and its incidence has been steadily rising. Surgery is the only curative option, but less than one-third of these patients are good candidates. Moreover, 5-year recurrence of HCC after surgery is around $50-75 \%$ depending on the series. Therefore, the idea of MAGE-1 and MAGE-3 being potentially immunogenic in HCC patients opens two avenues for immunotherapy: (i) active vaccination, or/and (ii) adoptive T-cell therapy with ex vivo expanded T-lymphocytes.

Evidence for T-cell reactivity after injection of dendritic cells pulsed with MAGE antigens has been reported in melanoma [15-18]. This has been the most powerful approach so far to active immunization, but there is ample scope for improvement since most tumors progressed with little practical therapeutic impact. Vaccination has been also tried with synthetic antigenic peptides, even without adjuvant, with evidence of some clinical activity but with unremarkable T-cell responses [10].

Adoptive T-cell therapy is gaining support in tumor therapy also, because techniques to select and expand T-cells in culture have improved. Patients with HCC undergoing adoptive transfer with mitogen-activated T-cells experienced much fewer relapses post-surgery than untreated controls [29]. Thus, the more specific MAGEbased immunotherapy has a potential role in eliminating micrometastatic disease and reducing tumor recurrence following surgery or ablative procedures.

In melanoma, pretreatment with non-myeloablative chemotherapy regimes increased the efficacy of reinfused pre-activated T-cells which undergo a vast expansion in vivo with resultant clinical efficacy in some patients [30]. Chemotherapy regimes are supposed to eliminate suppressor T-cells and/or competitors for scarce T-cell growth factors such as interleukins 7 and 15 [30].

Adoptive T-cell therapy using a single T-cell determinant seems to be less effective than using polyclonal T-cells covering various specificities [30,31]. The main reason seems to be that T-cells escape immunotherapy by downregulating the expression of antigen or antigen-presenting molecules [31]. Therefore search for other shared tumor antigens should continue in HCC. Apart from a polyclonal effector population, adoptive T-cell therapy will also benefit from de-bulking strategies that would both reduce tumor mass and lessen the effect of tumor factors detrimental to the immune system.

A combination of active immunization with a mixture of antigens followed by reinfusion of ex vivo expanded T-cells is, in our opinion, the most promising route ahead. The results by Zerbini et al. suggest that this approach may be feasible in a significant percentage of HCC patients. They also speculate that the HCC tissue may harbor factors that maintain T-cells anergic, and thus unable to attack malignant cells. The paradox of finding an expanded lymphocyte population infiltrating HCC along with concomitant disease progression deserves more attention in order to understand the mechanisms involved.

In conclusion, the discovery of a suitable molecular antigenic target in HCC should help in devising new immunotherapeutic strategies; these in turn could benefit patients, who very often lack any other treatment options.

\section{Acknowledgements}

Drs Borrás, Prieto, Bendandi and Lasarte are acknowledged for scientific discussion. We are grateful to Dr Diego Vergani for critical reading and English editing. Financial support was granted from MCYT (SAF02/0373 and SAF01/119), Gobierno de Navarra (Departamento de Salud) and Redes Temáticas de Investigación Cooperativa FIS (RETICs C03/10 and C03/02).

\section{References}

[1] Boon T, Cerottini JC, Van den Eynde B, van der Bruggen P, Van Pel A. Tumor antigens recognized by $\mathrm{T}$ lymphocytes. Annu Rev Immunol 1994;12:337-365.

[2] Van den Eynde B, Lethe B, Van Pel A, De Plaen E, Boon T. The gene coding for a major tumor rejection antigen of tumor P815 is identical to the normal gene of syngeneic DBA/2 mice. J Exp Med 1991;173: 1373-1384.

[3] van der Bruggen P, Traversari C, Chomez P, Lurquin C, De Plaen E, Van den Eynde B, et al. A gene encoding an antigen recognized by cytolytic T lymphocytes on a human melanoma. Science 1991;254: 1643-1647.

[4] Scanlan MJ, Gure AO, Jungbluth AA, Old LJ, Chen YT. Cancer/testis antigens: an expanding family of targets for cancer immunotherapy. Immunol Rev 2002;188:22-32.

[5] Boel P, Wildmann C, Sensi ML, Brasseur R, Renauld JC, Coulie P, et al. BAGE: a new gene encoding an antigen recognized on human melanomas by cytolytic T lymphocytes. Immunity 1995;2:167-175.

[6] Van den Eynde B, Peeters O, De Backer O, Gaugler B, Lucas S, Boon T. A new family of genes coding for an antigen recognized by autologous cytolytic $\mathrm{T}$ lymphocytes on a human melanoma. J Exp Med 1995;182:689-698.

[7] Ikeda H, Lethe B, Lehmann F, van Baren N, Baurain JF, de Smet C, et al. Characterization of an antigen that is recognized on a melanoma showing partial HLA loss by CTL expressing an NK inhibitory receptor. Immunity 1997;6:199-208.

[8] Tureci O, Sahin U, Pfreundschuh M. Serological analysis of human tumor antigens: molecular definition and implications. Mol Med Today 1997;3:342-349. 
[9] Reynolds SR, Oratz R, Shapiro RL, Hao P, Yun Z, Fotino M, et al. Stimulation of CD8 $+\mathrm{T}$ cell responses to MAGE-3 and Melan A/ MART-1 by immunization to a polyvalent melanoma vaccine. Int $\mathrm{J}$ Cancer 1997;72:972-976

[10] Marchand M, van Baren N, Weynants P, Brichard V, Dreno B, Tessier $\mathrm{MH}$, et al. Tumor regressions observed in patients with metastatic melanoma treated with an antigenic peptide encoded by gene MAGE3 and presented by HLA-A1. Int J Cancer 1999;80:219-230.

[11] Lasarte JJ, Sarobe P, Gullon A, Prieto J, Borras Cuesta F. Induction of cytotoxic $\mathrm{T}$ lymphocytes in mice against the principal neutralizing domain of HIV-1 by immunization with an engineered T-cytotoxic-Thelper synthetic peptide construct. Cell Immunol 1992;141:211-218.

[12] Weber JS, Hua FL, Spears L, Marty V, Kuniyoshi C, Celis E. A phase I trial of an HLA-A1 restricted MAGE-3 epitope peptide with incomplete Freund's adjuvant in patients with resected high-risk melanoma. J Immunother 1999;22:431-440.

[13] Mayordomo JI, Zorina T, Storkus WJ, Zitvogel L, Celluzzi C, Falo $\mathrm{LD}$, et al. Bone marrow-derived dendritic cells pulsed with synthetic tumour peptides elicit protective and therapeutic antitumour immunity. Nat Med 1995;1:1297-1302.

[14] Dhodapkar MV, Steinman RM, Sapp M, Desai H, Fossella C, Krasovsky J, et al. Rapid generation of broad T-cell immunity in humans after a single injection of mature dendritic cells. J Clin Invest 1999; $104: 173-180$.

[15] Thurner B, Haendle I, Roder C, Dieckmann D, Keikavoussi P, Jonuleit $\mathrm{H}$, et al. Vaccination with mage-3A1 peptide-pulsed mature, monocyte-derived dendritic cells expands specific cytotoxic T cells and induces regression of some metastases in advanced stage IV melanoma. J Exp Med 1999;190:1669-1678.

[16] Mackensen A, Herbst B, Chen JL, Kohler G, Noppen C, Herr W, et al. Phase I study in melanoma patients of a vaccine with peptide-pulsed dendritic cells generated in vitro from $\mathrm{CD} 34(+)$ hematopoietic progenitor cells. Int J Cancer 2000;86:385-392.

[17] Toungouz M, Libin M, Bulte F, Faid L, Lehmann F, Duriau D, et al Transient expansion of peptide-specific lymphocytes producing IFNgamma after vaccination with dendritic cells pulsed with MAGE peptides in patients with mage-A1/A3-positive tumors. J Leukoc Biol 2001;69:937-943.

[18] Banchereau J, Palucka AK, Dhodapkar M, Burkeholder S, Taquet N, Rolland A, et al. Immune and clinical responses in patients with metastatic melanoma to CD34(+) progenitor-derived dendritic cell vaccine. Cancer Res 2001;61:6451-6458.

[19] Schuler-Thurner B, Schultz ES, Berger TG, Weinlich G, Ebner S, Woerl P, et al. Rapid induction of tumor-specific type $1 \mathrm{~T}$ helper cells in metastatic melanoma patients by vaccination with mature, cryopreserved, peptide-loaded monocyte-derived dendritic cells. J Exp Med 2002;195:1279-1288.

[20] Marchand M, Punt CJ, Aamdal S, Escudier B, Kruit WH, Keilholz U, et al. Immunisation of metastatic cancer patients with MAGE-3 protein combined with adjuvant SBAS-2: a clinical report. Eur J Cancer 2003;39:70-77.

[21] Rosenberg SA, Yang JC, Schwartzentruber DJ, Hwu P, Marincola FM, Topalian SL, et al. Immunologic and therapeutic evaluation of a synthetic peptide vaccine for the treatment of patients with metastatic melanoma. Nat Med 1998;4:321-327.

[22] Sadanaga N, Nagashima H, Mashino K, Tahara K, Yamaguchi H, Ohta M, et al. Dendritic cell vaccination with MAGE peptide is a novel therapeutic approach for gastrointestinal carcinomas. Clin Cancer Res 2001;7:2277-2284.

[23] Yamashita N, Ishibashi H, Hayashida K, Kudo J, Takenaka K, Itoh K, et al. High frequency of the MAGE-1 gene expression in hepatocellular carcinoma. Hepatology 1996;24:1437-1440.

[24] Arina A, Tirapu I, Alfaro C, Rodriguez-Calvillo M, Mazzolini G, Inoges $\mathrm{S}$, et al. Clinical implications of antigen transfer mechanisms from malignant to dendritic cells. Exploiting cross-priming. Exp Hematol 2002;30:1355-1364.

[25] Zerbini A, Pilli M, Soliani P, Ziegler S, Pelosi G, Orlandini A, et al. Ex vivo characterization of tumor-derived melanoma antigen encoding gene-specific CD8 + cells in patients with hepatocellular carcinoma. J Hepatol 2004;40:102-109.

[26] Zhang L, Conejo-Garcia JR, Katsaros D, Gimotty PA, Massobrio M, Regnani $\mathrm{G}$, et al. Intratumoral $\mathrm{T}$ cells, recurrence, and survival in epithelial ovarian cancer. N Engl J Med 2003;348:203-213.

[27] Renkvist N, Castelli C, Robbins PF, Parmiani G. A listing of human tumor antigens recognized by $\mathrm{T}$ cells. Cancer Immunol Immunother 2001;50:3-15.

[28] Lee PP, Yee C, Savage PA, Fong L, Brockstedt D, Weber JS, et al. Characterization of circulating $\mathrm{T}$ cells specific for tumor-associated antigens in melanoma patients. Nat Med 1999;5:677-685.

[29] Takayama T, Sekine T, Makuuchi M, Yamasaki S, Kosuge T, Yamamoto J, et al. Adoptive immunotherapy to lower postsurgical recurrence rates of hepatocellular carcinoma: a randomised trial. Lancet 2000;356:802-807.

[30] Dudley ME, Rosenberg SA. Adoptive-cell-transfer therapy for the treatment of patients with cancer. Nat Rev Cancer 2003;3: 666-675.

[31] Yee C, Thompson JA, Byrd D, Riddell SR, Roche P, Celis E, et al. Adoptive $\mathrm{T}$ cell therapy using antigen-specific CD8 $+\mathrm{T}$ cell clones for the treatment of patients with metastatic melanoma: in vivo persistence, migration, and antitumor effect of transferred $\mathrm{T}$ cells. Proc Natl Acad Sci USA 2002;99:16168-16173. 